\title{
A multiprotein complex involved in chloroplast group II intron splicing
}

\author{
KARL PERRON, ${ }^{1}$ MICHEL GOLDSCHMIDT-CLERMONT, and JEAN-DAVID ROCHAIX
}

Departments of Molecular Biology and Plant Biology, University of Geneva, 1211 Geneva, Switzerland

\begin{abstract}
The psaA gene of the green alga Chlamydomonas reinhardtii consists of three exons that are widely separated on the chloroplast genome and transcribed independently. The exons are flanked by group II intron sequences. Maturation of the psaA mRNA requires two steps of splicing in trans between the transcripts of exons 1, 2, and 3. At least 14 nuclear loci and one chloroplast gene $(t s c A)$ are involved in this process. Recently the genes of three of these nuclear factors have been cloned. Raa3 is involved in the first trans-splicing reaction, and Raa1 and Raa2 are required for the second trans-splicing reaction. Here we show that Raa1 and Raa2 can be coimmunoprecipitated and that they are part of a high molecular weight complex of 400-500 kD. The size and integrity of the complex are affected by mutations in other complementation groups, suggesting that the corresponding proteins may also be components of this multiprotein complex or required for its assembly. Raa1 is also associated with a larger complex.
\end{abstract}

Keywords: Trans-splicing; group II intron; chloroplast; Chlamydomonas; protein complex

\section{INTRODUCTION}

As other photosynthetic eukaryotic cells, the green alga Chlamydomonas reinhardtii contains three distinct genetic systems located in the nucleus, chloroplast, and mitochondria. The biogenesis of the photosynthetic apparatus depends on a close coordination between the nuclear and chloroplast systems. Some of the subunits of the photosynthetic complexes are encoded by nuclear genes, translated on cytosolic ribosomes, and imported into the chloroplast, whereas other subunits are synthesized in the chloroplast (Rochaix 1996). Genetic analysis of the assembly of the photosynthetic machinery in Chlamydomonas and land plants has revealed a large set of nucleus-encoded factors that are required for different posttranscriptional steps including RNA stability and processing, splicing, and translation. A striking example of the dependence of chloroplast gene expression on nucleus-encoded factors is provided by the $p s a A$ gene of $C$. reinhardtii. This gene consists of three exons that are dispersed on the chloroplast genome and

Reprint requests to: Department of Molecular Biology, University of Geneva, 30, Quai Ernest Ansermet, 1211 Geneva, Switzerland; e-mail: Jean-David.Rochaix@molbio.unige.ch; fax: 41227026868.

${ }^{1}$ Present address: Department of Genetics and Microbiology, CMU, 9, Avenue de Champel, 1211 Geneva, Switzerland.

Article and publication are at http://www.rnajournal.org/cgi/doi/ 10.1261/rna.5237804. flanked by group II intron sequences (Kück et al. 1987). Each exon is transcribed independently (Choquet et al. 1988). Maturation of the psaA mRNA involves two transsplicing reactions and requires at least 14 nucleus-encoded factors (Goldschmidt-Clermont et al. 1990). Mutants deficient in this trans-splicing process can be grouped in three different classes based on their RNA phenotype. Class A mutants are deficient in the splicing of exons 2 and 3, class $\mathrm{C}$ mutant are affected in the splicing of exons 1 and 2, and class B mutants are deficient in both steps of trans-splicing. An unusual feature of the first $p s a A$ intron is that its middle part is provided by another locus of the chloroplast genome, called $t s c A$. It encodes a small RNA that, together with the $5^{\prime}$ - and $3^{\prime}$-intron transcripts, forms a trans-spliced tripartite intron (Goldschmidt-Clermont et al. 1991).

Fragmented group II introns also occur in vascular plants. Maturation of the chloroplast rps $12 \mathrm{mRNA}$ involves both cis- and trans-splicing, and the formation of several mitochondrial mRNAs in vascular plants requires transsplicing reactions (Bonen and Vogel 2001).

Besides their importance in chloroplast and mitochondrial biogenesis, group II introns are also of special interest because it is generally believed that they represent the evolutionary precursors of nuclear introns. They are found in diverse prokaryotic organisms, and in mitochondria and chloroplasts of plants and lower eukaryotes. The classical splicing mechanism of group II introns involves two trans- 
esterification steps as for nuclear introns. First, the $5^{\prime}$-exonintron junction is subject to nucleophilic attack by the branch-site adenosine to give rise to an intron-lariat intermediate. Subsequently, the $33^{\prime}$-intron-exon junction is attacked by the $3^{\prime}-\mathrm{OH}$ end of the cleaved exon, and the two exons are spliced together. Another pathway for group II intron splicing has been identified in which the first step occurs via hydrolysis and produces a linear excised intron (Jarrell et al. 1988; Podar et al. 1998). More recently, a third mechanism of splicing was described in which group II introns can be excised as circles (Murray et al. 2001).

Although a great deal is known about the molecular mechanisms of splicing of group II introns (Bonen and Vogel 2001), less is known on the protein factors involved in this process. It is well documented that some group II introns can undergo self-splicing reactions in vitro via a lariat intermediate under nonphysiological conditions (Michel and Ferat 1995). However, in vivo splicing requires the participation of protein factors, some of which are encoded by the intron itself and are called maturases (Lambowitz and Perlman 1990). These proteins were first identified in yeast mitochondria, and some of them act both as splicing factors by promoting the folding of the intron RNA into the catalytically active structure, and as reverse transcriptases in intron mobility (Lambowitz et al. 1999). Maturase-like proteins have also been identified and characterized in plastids (Liere and Link 1995). The recent genome sequencing projects of Arabidopsis and rice have revealed putative proteins resembling maturases encoded by nuclear genes, which may be imported into organelles to function in group II intron splicing (Mohr and Lambowitz 2003). Other factors have an indirect effect on splicing. Thus, mutations in the MRS2 gene that encodes a mitochondrial $\mathrm{Mg}^{2+}$ transporter in yeast affect the splicing of all mitochondrial group II introns (Bui et al. 1999; Gregan et al. 2001). A proper $\mathrm{Mg}^{2+}$ concentration is essential for the splicing process. Disruption of the MSS116 in yeast leads to a splicing defect of mitochondrial group I and II introns (Seraphin et al. 1989). This protein contains a RNA helicase domain and appears to stimulate splicing in an ATP-dependent manner (Niemer et al. 1995). In maize, several genes involved in chloroplast group II intron splicing have been identified. Crs1 is specifically required for the splicing of the chloroplast atpF intron (Till et al. 2001). Crs2 is required for the splicing of nine chloroplast introns (Jenkins et al. 1997). The Crs2 gene encodes a protein related to peptidyl-tRNA hydrolase. However, the protein appears to lack the hydrolase activity (Jenkins and Barkan 2001). Caf1 and Caf2 are two factors associated with Crs2 in intron ribonucleoprotein particles with distinct intron specificities (Ostheimer et al. 2003). Together with Crs1, they are part of a family of proteins found in plants, eubacteria, and archaebacteria that contain a basic repeated domain involved in RNA binding (Till et al. 2001; Ostheimer et al. 2003). In $C$. reinhardtii, the genes of three splicing factors have been cloned and characterized, Raal (M. Goldschmidt-Clermont, K. Perron, M. Rahire, and J.D. Rochaix, in prep.), Raa2 (previously called Maa2; Perron et al. 1999), and Raa3 (Rivier et al. 2001). Raa2 is involved in splicing of the second and third $p s a A$ exons and displays sequence similarity with pseudouridine synthases. However, this activity is not required for the trans-splicing reaction. Raa 3 is required to splice the first and second $p s a A$ exons. It encodes a protein of $176 \mathrm{kD}$ that does not show any sequence similarity to other known proteins except for a short stretch shared with pyridoxamine $5^{\prime}-\mathrm{P}$ oxidase.

It is apparent that several splicing factors display similarity with enzymes acting on RNA, and on tRNA in particular. Raa2 and Crs2, involved in group II intron splicing, are related to pseudouridine synthases and peptidyl-tRNA hydrolase, respectively (Perron et al. 1999; Jenkins and Barken 2001). The CYT-18 gene in Neurospora crassa and the NAM2 gene in Saccharomyces cerevisiae encode mitochondrial tyrosyl-tRNA synthetase and leucyl-tRNA synthetase, respectively, which are also required for splicing mitochondrial group I introns (Dujardin and Herbert 1997). It appears that the affinity for RNA of ancestral tRNA-binding proteins has been maintained during evolution and adapted for splicing (Lambowitz and Perlman 1990).

The mechanism of action of these proteins is not yet understood. It is likely that they act as RNA chaperones or splicing facilitators. Recent investigations indicate that some of them form complexes with RNA and with other protein factors. Raa3 is found in a $1700-\mathrm{kD}$ complex that contains $t s c A$ RNA and the transcript of the first $p s a A$ exon (Rivier et al. 2001). Crs1 and Crs2 are also found in complexes larger than $500 \mathrm{kD}$ that cosediment with their respective group II intron transcripts (Jenkins and Barkan 2001; Till et al. 2001). Two proteins of 61 and $31 \mathrm{kD}$ bind specifically to domain IV of a heterologous intron inserted in the C. reinhardtii chloroplast genome (Bunse et al. 2001). Ribonucleoprotein complexes containing pre-tRNA with group I and II introns have also been detected in tobacco chloroplasts (Nakamura et al. 1999).

Our previous work raised the possibility that Raa2 interacts with other trans-splicing factors (Perron et al. 1999). Here we show that Raa1 and Raa2 can be coimmunoprecipitated and that both proteins are part of a complex of $400-500 \mathrm{kD}$. As mutations in some of the other trans-splicing factors affect the stability or the size of this complex, it is probable that other proteins are associated with it, or involved in its assembly or stability. Moreover Raal is associated with a larger complex that contains RNA.

\section{RESULTS}

\section{Raa2 can be released from chloroplast membranes}

The Raa2 polypeptide was previously found to be associated with low-density membranes (LDMs) inside the chloroplast 
(Perron et al. 1999). These membranes could be involved in chloroplast mRNA metabolism and could be derived from the chloroplast envelope (Zerges and Rochaix 1998). The association between Raa2 and these LDMs does not appear to be mediated by hydrophobic interactions because nonionic detergents are unable to destabilize this association. Salts and ionic detergents fully solubilize Raa2, but are known to destabilize protein-protein interactions and could therefore also affect the integrity of a potential Raa2 protein complex. Ammonium sulfate at low concentration can release weakly associated proteins from membranes without affecting protein complexes. We therefore treated chloroplast membranes with different concentrations of ammonium sulfate and analyzed the insoluble and soluble fractions by immunoblotting (Fig. 1A). At $0.1 \mathrm{M}$ ammonium sulfate, the majority of Raa2 was recovered in the soluble fraction, and all of it was fully released with 0.4 to $0.5 \mathrm{M}$ ammonium sulfate (Fig. 1A).

\section{Raa 2 is part of a high molecular weight complex}

To test whether Raa2 is part of a protein complex, an extract prepared from total cell membranes treated with $0.5 \mathrm{M}$ ammonium sulfate was loaded on a sucrose density gradient. After centrifugation, 11 fractions were recovered and subjected to immunoblot analysis. Raa2 was present mainly in fractions 6,7 , and 8 with a peak in fraction 7 , corresponding to a molecular mass of $500 \mathrm{kD}$ (Fig. 1B, first row). As the molecular mass of Raa2 is only $40 \mathrm{kD}$, this result indicates that the protein is present in a high molecular weight complex.

Raa2 is required for the trans-splicing of psaA exons 2 and 3. To test whether a transcript of the second intron is associated with the Raa2 complex, the same experiment was performed with a strain containing a deletion extending over the $3^{\prime}$ part of intron 2 and exon 3 of psaA ( $\Delta$ exon3; Fischer et al. 1996). The distribution of Raa2 from this strain was undistinguishable from the wild type after sucrose density gradient centrifugation (Fig. 1B, second row). The same profile was observed by treating the protein extract with RNase A or by inhibiting RNase activity with heparin (Fig. 1B). These results indicate that the $500-\mathrm{kD}$ Raa2 complex does not contain RNA. Treatment of the extract with EDTA did not alter the complex, indicating that divalent cations are not required for its stability.

\section{The Raa2 protein complex is affected in several mutants deficient in trans-splicing}

It was previously shown that the level of Raa2 polypeptide is strongly reduced in several trans-splicing mutants belonging to other complementation groups (Perron et al. 1999). Because the stability of protein complexes is often compromised when one component is missing, this result raises the possibility that some of the other trans-splicing factors
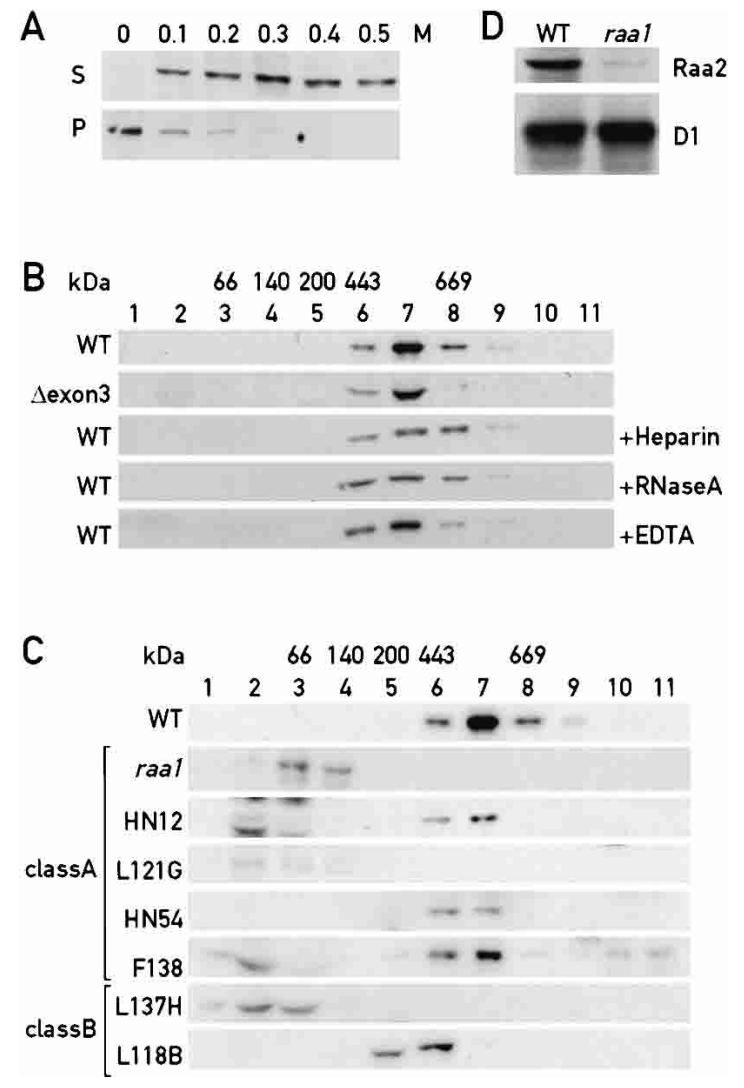

FIGURE 1. Raa2 is part of a high molecular weight complex. $(A)$ Release of Raa2 from chloroplast membranes by treatment with increasing concentrations of ammonium sulfate. (P) Insoluble pellet fraction; (S) soluble fraction. (B) Size fractionation of the Raa2 complex. Soluble protein extract obtained after $0.5 \mathrm{M}$ ammonium sulfate treatment was analyzed by sucrose gradient sedimentation. In all, 11 fractions were collected (lane 1, top; lane 11, bottom) and analyzed by immunoblotting using a polyclonal antiserum against Raa2. Treatment of the protein extracts with heparin, RNaseA, or EDTA is indicated on the right. Size markers are shown at the top. $(C)$ Analysis of the Raa2 complex in different class A and B mutants. Conditions were as in $B$. (D) Total proteins from the raal-314B mutant (raal) were analyzed by immunoblotting with antiserum against Raa2. Antiserum against D1 (a membrane protein from photosystem II) was used as the control.

could be part of the complex together with Raa2 or be required for its assembly and/or stability. To test this possibility, sucrose density gradient fractionations were performed with extracts from the recently characterized raal$314 B$ mutant deficient in exon 2-exon 3 splicing (M. Goldschmidt-Clermont, K. Perron, M. Rahire, and J.D. Rochaix, in prep.) and representative mutants of the four other class A complementation groups and of the two class B complementation groups (Fig. 1C). The Raa2 complex was missing in the raa1-314B mutant. Instead, Raa2 was found near the top of the sucrose gradient. Moreover, the amount of Raa2 was strongly reduced in the raal-314B mutant (Fig. 1D). The Raa2 complex was also absent in the L121G mutant, and only trace amounts of Raa2 protein were found at the top of the gradient. Thus, the L121G mutation leads to the 
destabilization of the complex and Raa2 can be degraded. Loss of the Raa2 complex was also observed in the class B mutant $\mathrm{L} 137 \mathrm{H}$, in which Raa2 was found exclusively at the top of the gradient. Interestingly, in the other class $\mathrm{B}$ mutant, L118B, in which Raa2 accumulates to wild-type levels, the Raa2 complex was slightly shifted toward the top of the gradient with a size of $\sim 400 \mathrm{kD}$. The $\mathrm{L} 118 \mathrm{~B}$ factor could be a component of the complex but does not appear to be necessary for its stability.

\section{Coimmunoprecipitation of Raa1 and Raa2}

The destabilization of the Raa2 complex in the raa1-314B mutant raised the possibility that Raa1 and Raa2 could be part of the same complex. Raal was recently characterized, the protein was tagged with HA (haemaglutinin), and a Raal antiserum was prepared (M. Goldschmidt-Clermont, K. Perron, M. Rahire, and J.D. Rochaix, in prep.). To test the possibility that Raa1 and Raa2 are associated with the same complex, coimmunoprecipitation experiments were performed. For this purpose, the coding sequence of the HA epitope was introduced into the Raa2 cDNA just upstream of the stop codon. The coding part of this CDNA was then inserted into an expression vector with the strong promoter, the 5'-UTR and the $3^{\prime}$-UTR of PsaD (Fischer and Rochaix 2001). This construct was used to rescue the raa2A18 mutant (Perron et al. 1999). In the transformants, the amount of tagged Raa2 protein was similar to or higher than the wild-type Raa2 protein expressed in its normal context (Fig. 2A). For the coimmunoprecipitation experiments, transformant 3.3 was used and named Raa2:HA. In this strain, the level of Raa2 polypeptide exceeds that of wild type.

The membrane fraction of Raa2:HA was treated with 0.5 $\mathrm{M}$ ammonium sulfate, and the soluble fraction was used directly for immunoprecipitation with the HA antibody. The immunoprecipitate was fractionated by SDS-PAGE and immunoblotted with either Raa2 or Raal antisera (M. Goldschmidt-Clermont, K. Perron, M. Rahire, and J.D. Rochaix, in prep.). In this way it was possible to detect the Raa2:HA polypeptide as well as Raal (Fig. 2B). Raal degradation products were also detected; a major band is labeled with an asterisk. No signal was detected in the raa2A18 mutant used as control except for the IgGs used for the immunoprecipitation. Similar immunoprecipitations were performed on extracts from the Raal:HA strain containing the HA epitope (M. Goldschmidt-Clermont, K. Perron, M. Rahire, and J.D. Rochaix, in prep.) with polyclonal antibodies directed against Raa2. Immunoblotting with HA antibody revealed the presence of Raa1:HA, but its absence in the raa1-314B control strain (Fig. 2B, right panel). In the converse immunoprecipitations with Raal antiserum, we were able to coimmunoprecipitate Raa2:HA (Fig. 2C). A small amount of Raal protein was detectable in the raa2 mutant strain, as seen by the presence of the major Raal
A
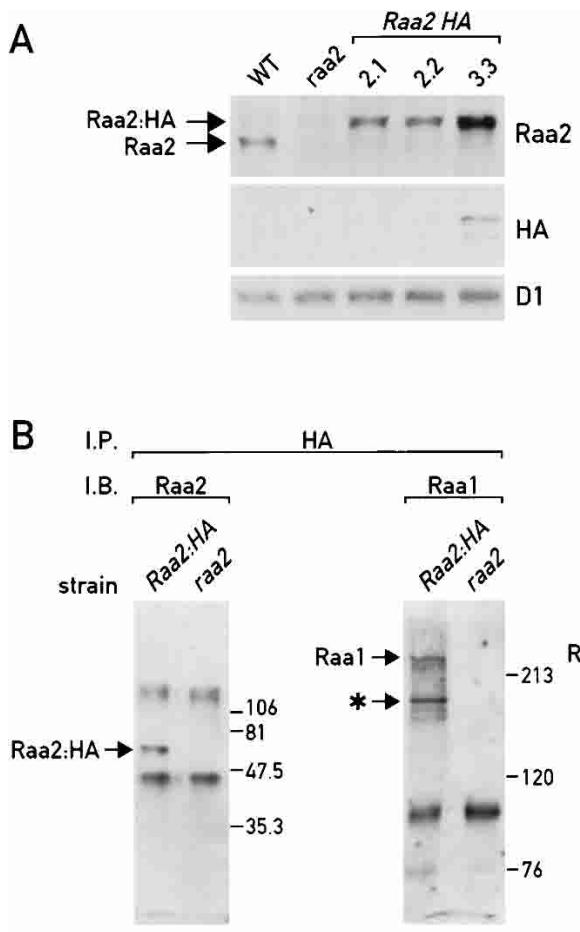

HA
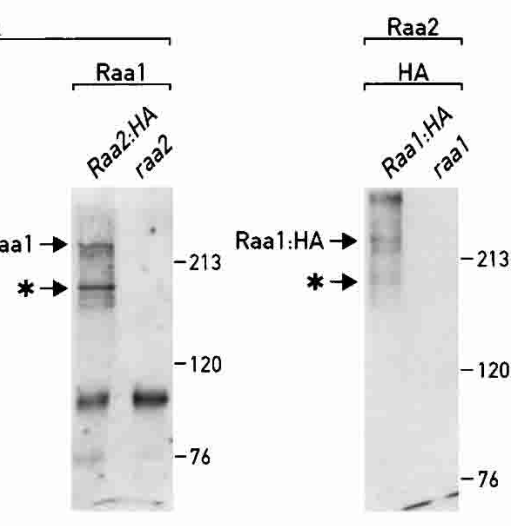

C

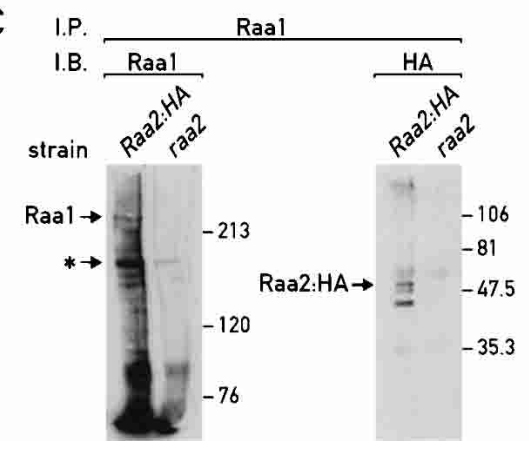

FIGURE 2. Coimmunoprecipitation of Raa2 and Raa1. (A) Immunoblot analysis of total protein extracts from wild-type (WT), raa2A18 (raa2), and raa2-A18 transformed with Raa2:HA. Three independent transformants are labeled 2.1, 2.2, and 3.3. The Raa2 and Raa2:HA proteins are marked with arrows. The blots were decorated with antisera against Raa2, HA, or D1 (control). (B) Immunoprecipitation (IP) of Raa2:HA using anti-HA (left panels) or anti-Raa2 antisera (right panel). Soluble protein extracts from the strains raa2-A18 (raa2), raa2-A18 rescued with Raa2:HA (Raa2:HA), raa1-314B (raa1), and raal-314B rescued with Raal-HA (Raal:HA) were immunoprecipitated as indicated. The immunoprecipitates were fractionated by SDS-PAGE, blotted, and reacted (IB) with antibodies directed against Raa2, Raa1, or HA. A major Raa1 degradation product is labeled with an asterisk $\left({ }^{*}\right)$. For the separation of Raa 2 and Raal, $10 \%$ or $6 \%$ polyacrylamide gels were used, respectively. $(C)$ Immunoprecipitation (IP) using Raal antiserum. The immunoprecipitates were immunoblotted with Raal and HA antisera as indicated.

degradation product marked by an asterisk, indicating that the loss of Raa2 leads to a decreased level of Raa1. No signal was detected with the HA antibody in the raa2 strain used as control (Fig. 2C). These results clearly show that it is possible to coimmunoprecipitate Raa1 and Raa2. 


\section{Cosedimentation of Raa1 and Raa2}

The results of Figure 1C indicate that Raa2 is part of a complex and that its integrity depends on several other factors including Raal. Attempts to rescue representative mutants of the five class A complementation groups by transformation with Raal failed, indicating that the raal$314 B$ mutant belongs to another complementation group. The Raal gene encodes a protein of $205 \mathrm{kD}$ (M. Goldschmidt-Clermont, K. Perron, M. Rahire, and J.D. Rochaix, in prep.). To further test whether Raal is part of the Raa2 complex, a strain carrying the Raa1 gene tagged with an HA epitope was used (Raa1:HA; M. Goldschmidt-Clermont, K. Perron, M. Rahire, and J.D. Rochaix, in prep.). Extracts obtained with $0.5 \mathrm{M}$ ammonium sulfate from this strain were fractionated by sucrose density gradient centrifugation. Under the conditions used, which were different from those in Figure 1C (see Materials and Methods), Raal was found in the same fractions as Raa2, corresponding to a molecular mass close to $400 \mathrm{kD}$, slightly smaller than that estimated in Figure 1C (Fig. 3A). It is possible that the HA tag induces changes in the complex and thus affects its sedimentation. Indeed, a small amount of Raa2 was found near the top of the gradient, suggesting that some of the Raa2 proteins cannot integrate into the complex in the presence of the HA-tagged Raal protein, or that this complex is less stable and tends to dissociate. The facts that HA-tagged Raa1 and Raa2 cosediment in the sucrose gradient and that sedimentation of Raa2 is affected in the absence of Raa1 (Fig. 1C) strongly suggests that they are part of the same 400-500-kD protein complex.

Although a large portion of the Raal polypeptide was found together with Raa2 in fractions 4 and 5 of the gradient (Fig. 3 ), smaller amounts of Raal were also detected in the higher molecular weight fractions. This raised the possibility that

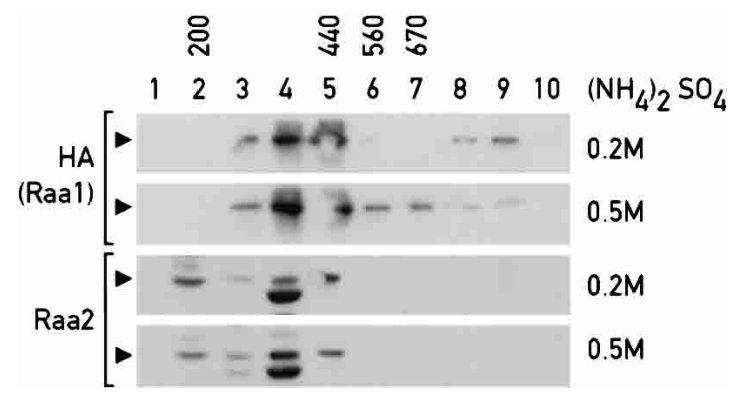

FIGURE 3. Raa2 and Raal complexes. Size fractionation of HAtagged Raa1 and Raa2. Soluble protein extracts obtained after ammonium sulfate treatment from the raal-314B strain rescued with Raa1:HA were fractionated by sucrose gradient centrifugation (see Materials and Methods). Fractions 1 and 10 correspond to the top and bottom fractions of the gradient, respectively. Size markers are indicated in kilodaltons at the top of the figure. Fractions were analyzed by immunoblotting using monoclonal HA antibodies (HA) or polyclonal Raa2 antibodies (Raa2). Raa1::HA and Raa2 proteins are indicated by wedges. The lower molecular weight band reacting with Raa2 antibodies is most likely due to a nonspecific interaction. larger complexes were destabilized because of the high salt extraction $(0.5 \mathrm{M}$ ammonium sulfate). Therefore, the release of the complex from the membrane was performed with 0.2 $\mathrm{M}$ ammonium sulfate, and the soluble fraction was centrifuged in a sucrose gradient. Under these milder conditions, Raal and Raa2 were found in the same lower molecular weight fractions (Fig. 3, fractions 4 and 5). However, a portion of Raal was observed in a higher molecular weight complex (Fig. 3, fractions 8 and 9). This complex is sensitive to RNase treatment, indicating that it contains RNA (M. Goldschmidt-Clermont, K. Perron, M. Rahire, and J.D. Rochaix, in prep.). Raa2 was undetectable in this larger complex.

\section{DISCUSSION}

The maturation of the chloroplast $p s a A$ mRNA involves two trans-splicing reactions and the participation of at least 14 nucleus-encoded factors, of which seven are required for the splicing of exons 1 and 2 (class $\mathrm{C}$ ), five are required for the splicing of exons 2 and 3 (class A), and two are required for both trans-splicing reactions (class B). The Raal and Raa2 factors both belong to class A (Perron et al. 1999; M. Goldschmidt-Clermont, K. Perron, M. Rahire, and J.D. Rochaix, in prep.). The results presented here clearly show that Raal and Raa2 are part of a multiprotein complex of 400$500 \mathrm{kD}$. This is based on the cofractionation of these two proteins during sucrose density gradient centrifugation, on the reduced accumulation of Raa2 in the raa1-314B mutant and the diminished levels of Raa1 in the raa2-A18 mutant, and on the reciprocal coimmunoprecipitations, which show that either protein can be coimmunoprecipitated with the other. It is not yet clear whether Raal and Raa2 interact directly or whether they interact indirectly through other components of the complex. Moreover, milder extraction of the complexes from the membrane reveal that Raal is associated with a larger molecular weight complex containing RNA (Fig. 3; M. Goldschmidt-Clermont, K. Perron, M. Rahire, and J.D. Rochaix, in prep.). It is possible that these different complexes result from a dynamic exchange of factors as observed during spliceosome formation in eukaryotic cells.

The accumulation of the $400-500-\mathrm{kD}$ Raa2 complex is drastically reduced in the L121G mutant that belongs to class A. Interestingly, the complex is also affected in the two class B mutants L137H and L118B. The complex is absent in the former and altered in size in the latter. One possibility is that these mutations affect the genes of other components of the Raa 2 complex: loss of some of the subunits could lead to destabilization and degradation of the complex. It is not entirely surprising that class B mutations, which affect trans-splicing of both introns, affect a complex that appears to be specifically involved in trans-splicing of the second intron. Some of the class B factors could be shared between ribonucleoprotein complexes specific for either the first or second trans-splicing reaction. The L118B mutation gives rise to a smaller complex, but Raa2 is not degraded. This 
could be explained if the L118B factor is not necessary for the stability of the complex but is required for the splicing of both $p s a A$ introns. It could represent a protein specific of group II introns analogous to the eight $\mathrm{Sm}$ proteins that are common to the U1, U2, U4, and U5 snRNPs of the nuclear spliceosome (Luhrmann et al. 1990). A factor, Crs2, required for splicing of nine group II introns has also been characterized in maize (Jenkins et al. 1997; Jenkins and Barkan 2001).

A hypothetical scheme of the $400-500-\mathrm{kD}$ Raa2 complex is shown in Figure 4. It could represent a chloroplast prespliceosomal complex of group II introns. The complex contains Raal and Raa2, but the stoichiometry of the components remains to be established. The three genetically defined factors pL121G, pL118G, and pL137H could also be part of the Raa2 complex. However, another possibility is that some of these factors are required for the assembly and/or stability of the complex without being part of the mature complex. It is also possible that the effect of the mutations is indirect, especially for the class B mutants. In the case of the class B mutant HN31, the factor affected by the mutation appears to be a bifunctional protein. It is involved both in the maturation of the $t s c A$ RNA required for splicing of exons 1 and 2, and also in the second transsplicing reaction (Hahn et al. 1998).

An RNA protein complex could be identified for Raal (M. Goldschmidt-Clermont, K. Perron, M. Rahire, and J.D. Rochaix, in prep.) but not for Raa2. We have been unable to detect any RNA-binding activity of Raa2 using UV crosslinking experiments with solubilized chloroplast extracts

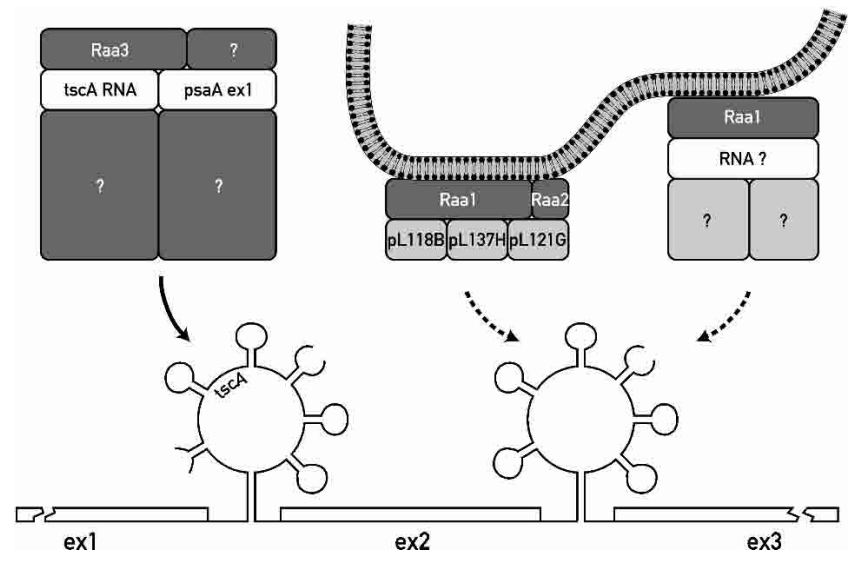

FIGURE 4. Chloroplast $p s a A$ splicing complexes. The Raa3 complex required for the first psaA trans-splicing reaction is present in the stroma, and consists of Raa3, tscA RNA, the $p s a A$ exon 1 precursor transcript with the $5^{\prime}$ part of intron 1 , and other unknown factors (Rivier et al. 2001). Although our data show that Raal and Raa2 are part of the $400-500-\mathrm{kD}$ complex associated with chloroplast membranes (drawn as a lipid bilayer), the presence of the other factors rests on indirect arguments (see text). Another possibility is that these other factors are not constituents of the complex but are required for its assembly and/or stability. Raal is also associated with a large molecular weight complex that contains RNA. The complexes are drawn according to their relative size. The $p s a A$ exons and the split group II introns are shown in the lower part. and transcripts of the second psaA intron. It is, however, likely that Raa2, which is required for splicing and is related to pseudouridine synthases, interacts in some way with RNA, perhaps only transiently. A different complex of $1700 \mathrm{kD}$ required for the splicing of exons 1 and 2 of $p s a A$ contains the Raa3 protein, $t s c A$ RNA, and the transcript of $p s a A$ exon 1 with the $5^{\prime}$ part of intron 1 (Fig. 4; Rivier et al. 2001). This ribonucleoprotein complex is found in the soluble fraction of the chloroplast, unlike the Raa2/Raal complex, which is associated with chloroplast membranes and can be released from the membranes by treatment with ammonium sulfate.

The fact that these two complexes have different chloroplast localizations could indicate that they act in different ways or in different steps of the psaA splicing pathway. It will be interesting to test whether the L118B mutation, which affects both trans-splicing reactions, alters the size of the $1700-\mathrm{kD}$ complex in the same way as that of the Raa2 complex. It is possible that the two trans-splicing reactions are spatially restricted, with the first reaction occurring in the stromal phase and the second reaction on the membrane. Membrane association could provide a link to translation. It is noteworthy that translation factors of C. reinhardtii have also been localized to plastid low-density membranes (LDMs), which could represent an intermediate during thylakoid membrane biogenesis (Zerges and Rochaix 1998). The trans-splicing reaction of the second $p s a A$ intron could occur on these membranes and could be coupled to the translation and integration of the PsaA protein into chloroplast membranes at an early step of photosystem I biosynthesis. Another interesting difference between these two complexes is that no other known class C or B trans-splicing mutation affects the level of Raa3 protein. This is in contrast to Raa2, which is strongly reduced in one mutant of class A (L121G) and one of class B (L137H).

Finally, it is possible that the $400-500-\mathrm{kD}$ Raa2 complex is involved in the storage of trans-splicing factors. In mammalian cells, splicing factors are stored in structures called speckles and are released at transcription and splicing sites (Misteli et al. 1997). The Raa2 complex could represent a protein storage complex of this sort that does not contain RNA. The existence of such a group II intron complex together with larger RNA-containing complexes would then suggest a dynamic partitioning of inactive and active splicing factors. Although their exact role remains to be elucidated, our work describes novel multiprotein complexes involved in chloroplast group II intron splicing and provides a basis for the biochemical isolation and characterization of other trans-splicing factors and the study of their functional role in the splicing process.

\section{MATERIALS AND METHODS}

\section{Strains and media}

Chlamydomonas reinhardtii wild-type and mutant strains were grown as described (Harris 1989). Trans-splicing mutants were 
described previously (Perron et al. 1999). The raal-314B mutant was isolated and characterized (M. Goldschmidt-Clermont, $\mathrm{K}$. Perron, M. Rahire, and J.D. Rochaix, in prep.).

\section{Nucleic acid techniques}

To insert the triple HA epitope, an StuI restriction site was created by PCR just upstream of the stop codon of the Raa2 ORF in plasmid pCD1. A 180-bp fragment containing the 3 '-end of the Raa 2 coding sequence was amplified by PCR with oligonucleotides A18/PmlI (5'-GTGCGATCGCTCATT-3') and NheI/StuI containing the StuI restriction site ( $5^{\prime}$-GGCGCTAGCGCCGCAGTGGT CAAGGCCTATGCGCGTGCCGTTGCAGCAC-3' ${ }^{\prime}$ ). After NheI digestion, this fragment was introduced in the Raa2 cDNA to replace the original PmlI/NheI fragment. A triple HA epitope was introduced and the construction verified by DNA sequencing (ABI prism, 377 DNA sequencer; Perkin Elmer). The full Raa2:HA ORF was amplified by PCR with oligonucleotides A18/RI, containing the EcoRI restriction site ( $5^{\prime}$-GGAATTCTCAAGGACTGCTAGC GGC-3'), and A18/NdeI, containing the NdeI restriction site (5' ACCACAGCCATATGCGGACGCGGGCAGGG-3'). This amplified ORF was digested with EcoRI and NdeI and inserted at the NdeI and EcoRI sites of the pGenD2 vector containing the PsaD flanking regions (Fischer and Rochaix 2001).

\section{Nuclear transformation}

Nuclear transformation of the class A mutants A18, HN12, L121G, HN54, and F138 were performed as described previously (Perron et al. 1999). The mutants were treated with autolysin to remove the cell wall and transformed with $2 \mu \mathrm{g}$ of the construct 518 (M. Goldschmidt-Clermont, K. Perron, M. Rahire, and J.D. Rochaix, in prep.), containing the Raal gene, or with $2 \mu \mathrm{g}$ of pJN4, conferring emetine resistance (Nelson et al. 1994), as a positive control.

\section{Raa2 solubilization and immunoblot analysis}

Immunoblot analysis and Raa2 solubilization were described previously (Perron et al. 1999). Briefly, to test Raa2 solubilization, chloroplast membranes were resuspended in chloroplast lysis buffer $\left(10 \mathrm{mM}\right.$ Tricine at $\mathrm{pH} 7.8,5 \mathrm{mM} \mathrm{MgCl}_{2}, 5 \mathrm{mM} \beta$-mercaptoethanol) containing protease inhibitors (PI: $5 \mathrm{mM} \varepsilon$-amino caproic acid, $1 \mathrm{mM}$ benzamidine $\mathrm{HCl}, 25 \mu \mathrm{g} / \mathrm{mL}$ pepstatin $\mathrm{A}, 10$ $\mu \mathrm{g} / \mathrm{mL}$ leupeptine) and one of the agents to be tested. The extract was incubated for $20 \mathrm{~min}$ on ice and centrifuged for $15 \mathrm{~min}$ at $50,000 \mathrm{~g}$ at $4^{\circ} \mathrm{C}$. The supernatant containing solubilized Raa2 and the pellet containing the nonsolubilized part were analyzed by immunoblotting.

\section{Coimmunoprecipitation}

Protein extract $(1 \mathrm{mg})$, prepared as described for sucrose gradient analysis, was preincubated in $500 \mu \mathrm{L}$ of TNX100 (Tris-HCl $50 \mathrm{mM}$ at $\mathrm{pH} 7.4,100 \mathrm{mM} \mathrm{NaCl}, 0.5 \%$ [w/v] Triton X-100) with $25 \mu \mathrm{L}$ of protein $\mathrm{G}$ agarose (Boehringer Mannheim) during $6 \mathrm{~h}$ on a rolling wheel at $4^{\circ} \mathrm{C}$ and then centrifuged ( $5 \mathrm{~min}$ in a microfuge). The supernatant was transferred to a new tube and incubated for $16 \mathrm{~h}$ in the same conditions with primary antibody directed against Raa1, Raa2, or HA epitope (HA-11; Eurogentec). Protein G agarose $(25 \mu \mathrm{L})$ was added, and the incubation was continued for $3 \mathrm{~h}$ at $4^{\circ} \mathrm{C}$. After a 5-min microfuge centrifugation, the pellet was washed five times in TNX100 and twice in $50 \mathrm{mM}$ Tris- $\mathrm{HCl}(\mathrm{pH}$ 7.4; 15-sec microfuge centrifugations between each wash). The pellet was resuspended in SDS gel loading buffer, boiled for $5 \mathrm{~min}$, and centrifuged (microfuge for $5 \mathrm{~min}$ ), and the supernatant was analyzed by SDS-PAGE gel and immunoblotting.

\section{Sucrose density gradient centrifugation}

Protein extracts for sedimentation on sucrose density gradients were prepared as follows: a pellet containing $5 \times 10^{8}$ cells was resuspended in $10 \mathrm{~mL}$ of $\mathrm{HKM}(20 \mathrm{mM}$ HEPES-KOH at $\mathrm{pH} 7.8$, $50 \mathrm{mM} \mathrm{KCl}, 10 \mathrm{mM} \mathrm{MgCl}$ ) containing protease inhibitor (PI). Cells were broken by freezing and thawing and centrifuged for 20 min at 10,000 rpm (HB6; Sorvall) at $4^{\circ} \mathrm{C}$. The pellet was resuspended in $2 \mathrm{~mL}$ of $\mathrm{HKM}+\mathrm{PI}$ containing $0.5 \mathrm{M}$ ammonium sulfate and incubated for $20 \mathrm{~min}$ on ice. Alternatively, $0.2 \mathrm{M}$ ammonium sulfate was used to preserve the larger complexes (Fig. 3). The extract was then centrifuged at $100,000 \mathrm{~g}$ for $20 \mathrm{~min}$, and the supernatant was loaded on a sucrose gradient. For the experiment shown in Figures 1 and 3, heparin $(0.5 \mathrm{mg} / \mathrm{mL})$ or RNase A $(0.5$ $\mathrm{mg} / \mathrm{mL}$ ) was added in HKM buffer for breaking the cells. For EDTA treatment, HK buffer (HMK without $\mathrm{Mg}^{2+}$ ) containing 10 mM EDTA was used.

Extract $(1 \mathrm{~mL})$ was loaded on a $10-\mathrm{mL}$ linear sucrose gradient (0.1-1.3 M) in HKM buffer (or in HK plus $10 \mathrm{mM}$ EDTA) and centrifuged at $145,000 \mathrm{~g}$ (SW40; Beckmann) for $16 \mathrm{~h}$ at $4^{\circ} \mathrm{C}$ (Fig. 1). Fractions ( $1 \mathrm{~mL}$ ) were collected and numbered from 1 (top) to 11 (bottom), sample number 1 corresponding to the volume of protein extract $(1 \mathrm{~mL})$ loaded on the gradient. Molecular weight standards from Sigma were used for calibration (Sigma Aldrich MW-GF-70 kit). Each fraction was precipitated by adding $100 \mu \mathrm{L}$ of trichloroacetic acid (75\%) and incubated for $30 \mathrm{~min}$ on ice. After a 15-min microfuge centrifugation, the pellet was washed once with ice cold acetone, dried in air, and resuspended in protein SDS gel loading buffer. The acrylamide concentration for SDS-PAGE was 10\% (for Raa2 detection) or 6\% (for Raal detection). The conditions used for the experiments shown in Figure 3 were similar except that the extract was centrifuged at $145,000 \mathrm{~g}$ for $17 \mathrm{~h}$. In these conditions, the Raa 2 complex was found in fractions corresponding to a molecular mass near $400 \mathrm{kD}$ rather than $500 \mathrm{kD}$.

\section{ACKNOWLEDGMENTS}

The authors thank N. Roggli for preparing the figures. This work was supported by grant 3100-067763.02 from the Swiss National Fund.

The publication costs of this article were defrayed in part by payment of page charges. This article must therefore be hereby marked "advertisement" in accordance with 18 USC section 1734 solely to indicate this fact.

Received November 20, 2003; accepted January 13, 2004. 


\section{REFERENCES}

Bonen, L. and Vogel, J. 2001. The ins and outs of group II introns. Trends Genet. 17: 322-331.

Bui, D.M., Gregan, J., Jarosch, E., Ragnini, A., and Schweyen, R.J. 1999. The bacterial magnesium transporter CorA can functionally substitute for its putative homologue Mrs2p in the yeast inner mitochondrial membrane. J. Biol. Chem. 274: 20438-20443.

Bunse, A.A., Nickelsen, J., and Kück, U. 2001. Intron-specific RNA binding proteins in the chloroplast of the green alga Chlamydomonas reinhardtii. Biochim. Biophys. Acta 1519: 46-54.

Choquet, Y., Goldschmidt-Clermont, M., Girard-Bascou, J., Kück, U., Bennoun, P., and Rochaix, J.D. 1988. Mutant phenotypes support a trans-splicing mechanism for expression of the tripartite psaA gene in the C. reinhardtii chloroplast. Cell 52: 903-913.

Dujardin, G. and Herbert, C.J. 1997. Aminoacyl tRNA synthetases involved in group I intron splicing. In Ribosomal RNA and group I introns (eds. R. Green and R. Schroeder), pp. 179-198. Landes Bioscience, Austin, TX.

Fischer, N. and Rochaix, J.D. 2001. The flanking regions of PsaD drive efficient gene expression in the nucleus of the green alga Chlamydomonas reinhardtii. Mol. Genet. Genomics 265: 888-894.

Fischer, N., Stampacchia, O., Redding, K., and Rochaix, J.D. 1996. Selectable marker recycling in the chloroplast. Mol. Gen. Genet. 251: 373-380.

Goldschmidt-Clermont, M., Girard-Bascou, J., Choquet, Y., and Rochaix, J.D. 1990. Trans-splicing mutants of Chlamydomonas reinhardtii. Mol. Gen. Genet. 223: 417-425.

Goldschmidt-Clermont, M., Choquet, Y., Girard-Bascou, J., Michel, F., Schirmer-Rahire, M., and Rochaix, J.D. 1991. A small chloroplast RNA may be required for trans-splicing in Chlamydomonas reinhardtii. Cell 65: 135-143.

Gregan, J., Bui, G.J., Pillich, R., Fink, M., Zsurka, G., and Schweyen, R.J. 2001. The mitochondrial inner membrane protein Lpe10p, a homologue of Mrs2p, is essential for magnesium homeostasis and group II intron splicing in yeast. Mol. Gen. Genet. 264: 773-781.

Hahn, D., Nickelsen, J., Hackert, A., and Kück, U. 1998. A single nuclear locus is involved in both chloroplast RNA trans-splicing and $3^{\prime}$ end processing. Plant J. 15: 575-581.

Harris, E.H. 1989. The Chlamydomonas sourcebook. A comprehensive guide to biology and laboratory use. Academic Press, San Diego.

Jarrell, K.A., Peebles, C.L., Dietrich, R.C., Romiti, S.L., and Perlman, P.S. 1988. Group II intron self-splicing. Alternative reaction conditions yield novel products. J. Biol. Chem. 263: 3432-3439.

Jenkins, B.D. and Barkan, A. 2001. Recruitment of a peptidyl-tRNA hydrolase as a facilitator of group II intron splicing in chloroplasts. EMBO J. 20: 872-879.

Jenkins, B.D., Kulhanek, D.J., and Barkan, A. 1997. Nuclear mutations that block group II RNA splicing in maize chloroplasts reveal several intron classes with distinct requirements for splicing factors. Plant Cell 9: 283-296.

Kück, U., Choquet, Y., Schneider, M., Dron, M., and Bennoun, P. 1987. Structural and transcriptional analysis of two homologous genes for the P700 chlorophyll $a$-apoproteins in Chlamydomonas reinhardtii: Evidence for in vivo trans splicing. EMBO J. 6: 21852195.

Lambowitz, A.M. and Perlman, P.S. 1990. Involvement of aminoacyltRNA synthetases and other proteins in group I and group II intron splicing. Trends Biochem. Sci. 15: 440-444.

Lambowitz, A.M., Caprara, M.G., Zimmerly, S., and Perlman, P.S. 1999. Group I and group II ribozymes as RNPs: Clues to the past and guides to the future. In The RNA world (eds. R.F. Gesteland et al.), pp. 451-485. Cold Spring Harbor Laboratory Press, Cold Spring Harbor, NY.

Liere, K. and Link, G. 1995. RNA-binding activity of the matK protein encoded by the chloroplast trnK intron from mustard (Sinapis alba L.). Nucleic Acids Res. 23: 917-921.

Luhrmann, R., Kastner, B., and Bach, M. 1990. Structure of spliceosomal snRNPs and their role in pre-mRNA splicing. Biochim. Biophys. Acta 96: 375-387.

Michel, F. and Ferat, J.L. 1995. Structure and activities of group II introns. Annu. Rev. Biochem. 64: 435-461.

Misteli, T., Caceres, J.F., and Spector, D.L. 1997. The dynamics of a pre-mRNA splicing factor in living cells. Nature 387: 523-527.

Mohr, G. and Lambowitz, A. 2003. Putative proteins related to group II intron reverse transcriptase/maturases are encoded by nuclear genes in higher plants. Nucleic Acids Res. 31: 647-652.

Murray, H.L., Mikheeva, S., Coljee, V.W., Turczyk, B.M., Donahue, W.F., Bar-Shalom, A., and Jarrell, K.A. 2001. Excision of group II introns as circles. Mol. Cell 8: 8: 201-211.

Nakamura, T., Ohta, M., Sugiura, M., and Sugita, M. 1999. Chloroplast ribonucleoproteins are associated with both mRNAs and intron-containing precursor tRNAs. FEBS Lett. 460: 437-441.

Nelson, J.A., Savereide, P.B., and Lefebvre, P.A. 1994. The CRY1 gene in Chlamydomonas reinhardtii: Structure and use as a dominant selectable marker for nuclear transformation. Mol. Cell. Biol. 14: 4011-4019.

Niemer, I., Schmelzer, C., and Borner, G.V. 1995. Overexpression of DEAD box protein pMSS116 promotes ATP-dependent splicing of a yeast group II intron in vitro. Nucleic Acids Res. 23: 2966-2972.

Ostheimer, G.J., Williams-Carrier, R., Belcher, S., Osborne, E., Gierke, J., and Barkan, A. 2003. Group II intron splicing factors derived by diversification of an ancient RNA-binding domain. EMBO J. 22: 3919-3929.

Perron, K., Goldschmidt-Clermont, M., and Rochaix, J.D. 1999. A factor related to pseudouridine synthases is required for chloroplast group II intron trans-splicing in Chlamydomonas reinhardtii. EMBO J. 18: 6481-6490.

Podar, M., Chu, V.T., Pyle, A.M., and Perlman, P.S. 1998. Group II intron splicing in vivo by first-step hydrolysis. Nature 391: 915918.

Rivier, C., Goldschmidt-Clermont, M., and Rochaix, J.D. 2001. Identification of an RNA-protein complex involved in chloroplast group II intron trans-splicing in Chlamydomonas reinhardtii. EMBO J. 20: 1765-1773.

Rochaix, J.D. 1996. Post-transcriptional regulation of chloroplast gene expression in Chlamydomonas reinhardtii. Plant Mol. Biol. 32: 327-341.

Seraphin, B., Simon, M., Boulet, A., and Faye, G. 1989. Mitochondrial splicing requires a protein from a novel helicase family. Nature 337: 84-87.

Till, B., Schmitz-Linneweber, C., Williams-Carrier, R., and Barkan, A. 2001. CRS1 is a novel group II intron splicing factor that was derived from a domain of ancient origin. RNA 7: 1227-1238.

Zerges, W. and Rochaix, J.D. 1998. Low density membranes are associated with RNA-binding proteins and thylakoids in the chloroplast of Chlamydomonas reinhardtii. J. Cell. Biol. 140: 101-110. 

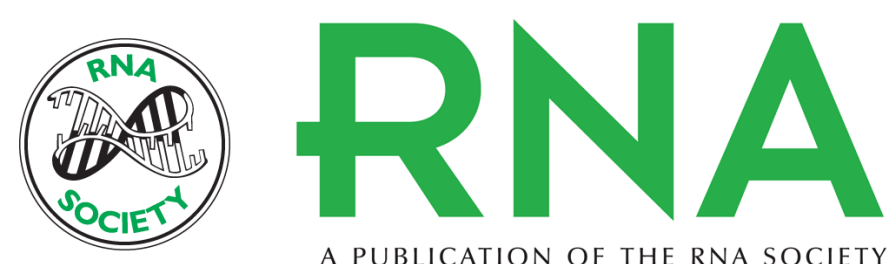

A PUBLICATION OF THE RNA SOCIETY

\title{
A multiprotein complex involved in chloroplast group II intron splicing
}

\author{
KARL PERRON, MICHEL GOLDSCHMIDT-CLERMONT and JEAN-DAVID ROCHAIX
}

RNA 2004 10: 704-711

References This article cites 30 articles, 10 of which can be accessed free at:

http://rnajournal.cshlp.org/content/10/4/704.full.html\#ref-list-1

License

Email Alerting Receive free email alerts when new articles cite this article - sign up in the box at the Service top right corner of the article or click here.

To subscribe to $R N A$ go to:

http://rnajournal.cshlp.org/subscriptions 